\title{
The European Flood Alert System - Part 1: Concept and development
}

\author{
J. Thielen ${ }^{1}$, J. Bartholmes ${ }^{1}$, M.-H. Ramos ${ }^{1,2}$, and A. de Roo ${ }^{1}$ \\ ${ }^{1}$ EC, Joint Research Centre, Institute for Environment and Sustainability, Via Fermi 2749, 21027 Ispra (VA), Italy \\ ${ }^{2}$ Parc de Tourvoie, BP 4492163 Antony Cedex, France
}

Received: 14 December 2007 - Published in Hydrol. Earth Syst. Sci. Discuss.: 6 February 2008

Revised: 2 December 2008 - Accepted: 14 January 2009 - Published: 5 February 2009

\begin{abstract}
This paper presents the development of the European Flood Alert System (EFAS), which aims at increasing preparedness for floods in trans-national European river basins by providing local water authorities with mediumrange and probabilistic flood forecasting information 3 to 10 days in advance. The EFAS research project started in 2003 with the development of a prototype at the European Commission Joint Research Centre (JRC), in close collaboration with the national hydrological and meteorological services. The prototype covers the whole of Europe on a $5 \mathrm{~km}$ grid. In parallel, different high-resolution data sets have been collected for the Elbe and Danube river basins, allowing the potential of the system under optimum conditions and on a higher resolution to be assessed. Flood warning lead-times of 3-10 days are achieved through the incorporation of medium-range weather forecasts from the German Weather Service (DWD) and the European Centre for Medium-Range Weather Forecasts (ECMWF), comprising a full set of 51 probabilistic forecasts from the Ensemble Prediction System (EPS) provided by ECMWF. The ensemble of different hydrographs is analysed and combined to produce early flood warning information, which is disseminated to the hydrological services that have agreed to participate in the development of the system. In Part 1 of this paper, the scientific approach adopted in the development of the system is presented. The rational of the project, the systems set-up, its underlying components, basic principles and products are described. In Part 2, results of a detailed statistical analysis of the performance of the system are shown, with regard to both probabilistic and deterministic forecasts.
\end{abstract}

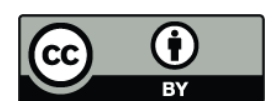

Correspondence to: J. Thielen (jutta.thielen@jrc.it)

\section{Introduction}

Over the last decades severe fluvial floods with a transnational dimension have taken place in Europe, such as the Rhine-Meuse floods in 1993 and 1995, the Oder floods in 1997, and the Po floods in 1994 and 2000. Historic floods affected the Elbe and the Danube river basins in 2002 (Brázdil et al., 2005; Yiou et al., 2006; Toothill, 2002). In 2005, widespread and repeated flooding was again observed in several tributaries to the Danube river basin, particularly in Switzerland and Austria (de Roo et al., 2006) and in the lower Danube countries (Romania and Bulgaria). Only one year later, record floods hit again the Elbe and the Danube river basins in spring 2006 (ICPDR, 2006). The European Environmental Agency estimated that floods in Europe between 1998 and 2002 caused about 700 deaths, the displacement of about half a million people and at least 25 billion Euros in insured economic losses (EEA, 2003). A study by Bakker (2007) suggests that transboundary floods are typically more severe in their magnitude, affect larger areas, result in higher death tolls, and cause more financial damage than non-shared river floods do. The repetitive occurrence of such disastrous floods prompts the investigation of new strategies for flood prevention and protection, with focus on coordinated actions among countries sharing the same river basin.

Preventive measures such as the construction of reservoirs, polders or dykes, aimed at reducing the impact of floods, have high priority for the national water authorities. Although these measures may attenuate the impact of floods, it is unlikely that floods can ever be totally prevented. Furthermore, within a changing climate, precipitation patterns are also likely to change (see, for example, Milly et al., 2002; Palmer and Raisanen, 2002; Lehner et al., 2006; Goubanova and $\mathrm{Li}, 2007$; and references therein) and the preventive measures already in place may need to be revised and adapted to the new hydro-meteorological conditions.

Published by Copernicus Publications on behalf of the European Geosciences Union. 
When preventive measures are not sufficient, flood damage can still be reduced through raised preparedness. Unfortunately, precipitation, in most cases the driving factor for floods, cannot be skilfully forecasted more than 2-3 days in advance. In a study based on forecasts from the European Centre for Medium-Range Weather Forecasts, Buizza et al. (1999) showed that, although the skill in weather forecasting has generally increased to 5-6 days, e.g. for temperature, it is only of the order of 2-3 days for precipitation. In particular, in the case of extreme rainfalls, which are of special interest to flood forecasters, the lead-time for skilled forecasts decreases even further.

However, this lead-time for skilled precipitation forecasting can be extended by exploring ensemble prediction systems (EPS) (e.g. Tracton and Kalnay, 1993; Molteni et al., 1996). Although produced by some meteorological services as early as the 1980s (Molteni et al., 1996), it is only recently that EPS have been explored for flood forecasting purposes. In Europe, the EFFS ${ }^{1}$ project (2000-2003) was one of the first large European research projects to look into the potential of using medium-range weather forecasts, including EPS, for flood forecasting in large trans-national river basins, with the aim of extending the early warning time (de Roo et al, 2003, Gouweleeuw et al., 2004).

In 2004, an international initiative called HEPEX ${ }^{2}$ was launched. HEPEX is an international effort that brings together meteorological and hydrological communities to develop advanced probabilistic hydrological forecasting techniques that use weather and climate ensemble forecasts (Hamill et al., 2005; Schaake et al., 2006; Schaake et al., 2007; Franz et al., 2005; Thielen et al., 2008).

Recent research results from HEPEX are encouraging and demonstrate the potential benefit of probabilistic weather forecasts over deterministic ones for flood forecasting in large river basins (Thielen et al., 2007; Buizza, 2008; Bogner and Kalas, 2008; Gebhardt et al., 2008; Marty et al., 2008; Pappenberger et al., 2008b; Schalk et al., 2008; Tucci et al., 2008; Zappa et al., 2008). Roulin (2007) demonstrated that EPS-based flood forecasting can also be valuable for small river basins, while advances in limited area EPS modelling may provide even better quantitative precipitation estimates also for small basins (Marsigli et al., 2001; Marsigli et al., 2005; Tibaldi et al., 2006).

The benefit of medium-range probabilistic flood forecasts for hydrological services lies first of all in the earlier knowledge that a possibility for a flood event to occur exists. It can for example lead to the discussion of different flood event scenarios, as well as possible responses and actions; to the re-arrangement of working schedules to have sufficient people on stand-by; and to enhanced monitoring of the meteorological and hydrological conditions over the coming days.

\footnotetext{
${ }^{1}$ European Flood Forecasting System

${ }^{2}$ Hydrological Ensemble Prediction Experiment (see http://hydis8.eng.uci.edu/hepex)
}

In case subsequent forecasts do not confirm the previous alert, forecasters can return to business-as-usual. Adverse effects from earlier warning are therefore minimal. In the opposite case, if a pre-alert is confirmed as the forecasted event approaches the forecast date, flood forecasters will be better prepared to initiate any necessary emergency procedure and there will be a gain in time when analysing the short-term and more precise - forecasts.

Earlier warning can therefore help in reducing the level of stress in the forecasting centres. Research has shown that the negative effects of stress on decision-making under time pressure and fatigue due to overwork in the operational centres during a flood event should not be underestimated (Kowalski-Trakofler et al., 2003; Paton and Flin, 1999).

In 2003 the European Commission started the development of a European Flood Alert System (EFAS), following the devastating Elbe and Danube floods in 2002. EFAS aims to simulate hydrological processes in trans-national river basins and to provide harmonized flood information across Europe.

This paper is Part 1 of two articles describing the European Flood Alert System. Part 1 presents the concept of EFAS, its underlying structure, development and forecasting products. In Part 2 (Bartholmes et al., 2009) the performance of the pre-operational EFAS system is analysed for a two-year period.

\section{General framework}

EFAS is part of a strategy for improved disaster management in Europe to reduce the impact of transnational floods through early warning. This can be achieved by first complementing Member States activities on flood preparedness, which means by providing National hydrological services with early flood information in addition to their own local and, mostly often, short-range forecasting information. Such complementary data can be catchment-based information beyond administrative boundaries, probabilistic flood information with lead-times up to 15 days, as well as results from a different hydrological model for comparison with the local simulations. Secondly, by providing the European Commission with an overview of ongoing and expected floods in Europe, an early-warning flood forecasting system can be useful for crisis management in the case of large trans-national flood events that might need intervention on an international level.

During its development stage, EFAS focused on providing additional information to the national hydrological services. As illustrated in Fig. 1, this stage was divided into five phases: (1) Assessment of scientific feasibility; (2) Identification of operational end-user needs; (3) Prototype development and research; (4) Preparation for transfer of operational system; (5) Running of operational system. These phases are described in the next Sections. 


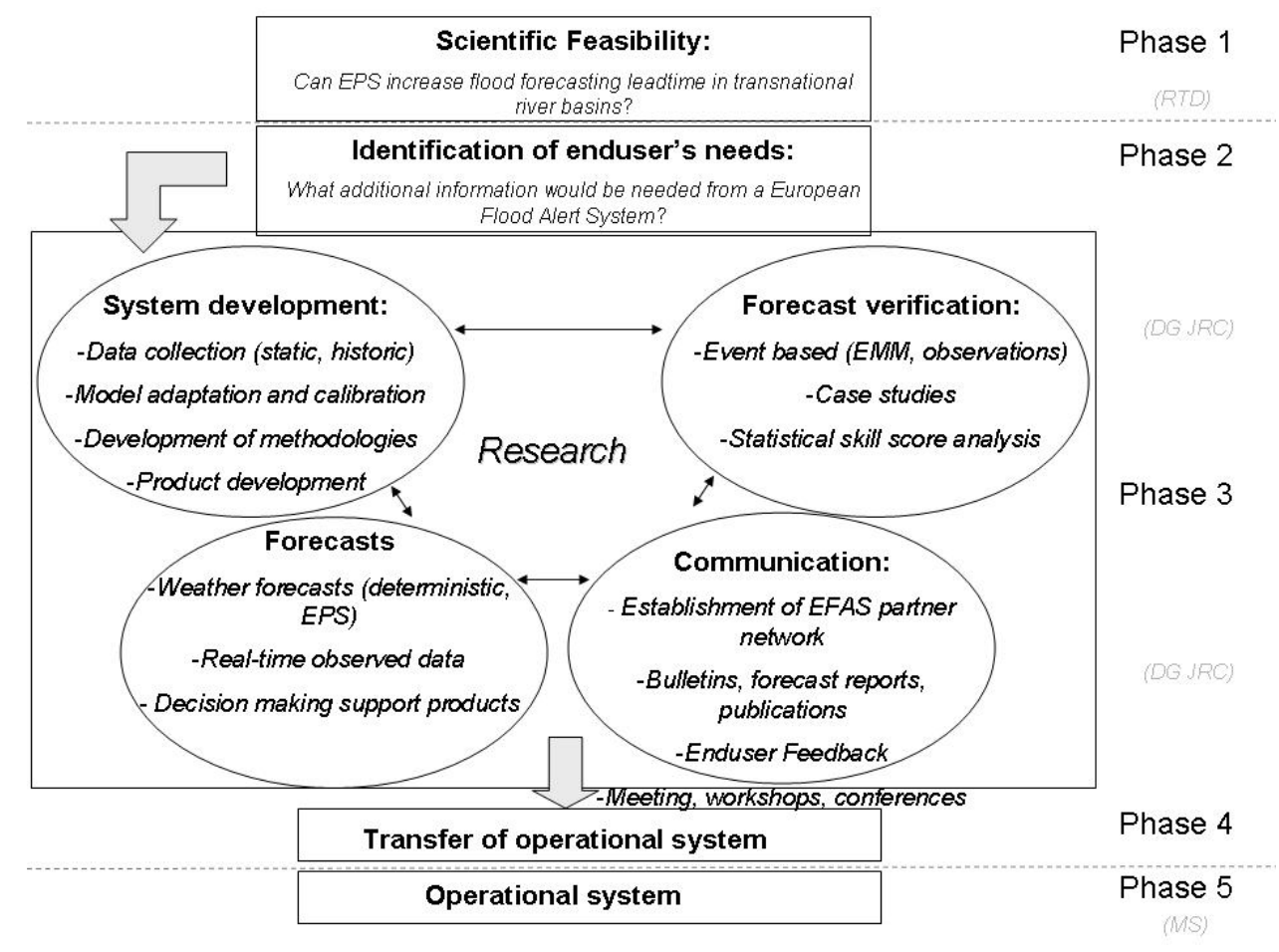

Fig. 1. General framework of the European Flood Alert System.

\section{Development of the European Flood Alert System}

\subsection{Phase 1: Scientific feasibility study}

The European Flood Forecasting System (EFFS, 2000-2003) was a research project under the 5th Framework Programme of the European Commission with 19 partners from meteorological and hydrological services, research institutes and operational services (Kwadijk, 2003; de Roo et al., 2003; Gouweleeuw et al., 2004). It was a pioneering project on probabilistic flood forecasting based on EPS in Europe. Four trans-national flood events for which observational data were available were selected as case studies and for those periods EPS forecasts were rerun by the European Centre for Medium Range Weather Forecasting (ECMWF) at state-ofthe-art resolution. Results showed clearly that, in the cases of the Meuse flood in 1995 and the Po flood in 1994, EPSbased flood forecasts provided early warning of the order of 6-8 days (Bartholmes and Todini, 2005; Gouweleeuw et al., 2005). In the case of the Odra flood in 1997, the achieved lead-time did not exceed 2-3 days. One drawback of the EFFS project was that the project could focus only on a small number of severe flood events, making the assessment of the ratio between hits, false alarms and misses impossible.
3.2 Phase 2: Identification of enduser needs

A survey of the current practices and future needs of the National water authorities for the Elbe and the Danube river basins in 2003 (Thielen et al., 2003) showed that EFAS could complement national systems with the following information:

i) Extension of lead-times. Typically, the achieved flood forecasting lead-times were 2-3 days, while the desired forecast lead-times exceeded the existing ones by at least 1 day.

ii) Interpretation of probabilistic weather and flood information. In 2003, all authorities with access to EPS information used them qualitatively only because first, the computational burden to run all EPS through their forecasting models was technically not possible, and second, it was felt that there was not sufficient expertise to analyse and interpret the results appropriately. Using all EPS for flood forecasting, interpreting the results and presenting them in a concise and easy to understand way was therefore seen as a definite role for EFAS.

iii) Catchment-based information. Flood forecasters noted that they would appreciate having an overview of the flood situation in upstream and neighbouring areas.

iv) Sharing of information and data. Data infrastructure is particularly fragmented in Europe, leading to diverse 
Table 1. EFAS input data in the period 2005/2006 where $\mathrm{P}$ stands for precipitation, $\mathrm{T}$ for mean daily temperature, $E_{0}$ for potential evaporation over bare soil, $E T_{0}$ potential evapotranspiration, and $E S_{0}$ potential evaporation over vegetated surfaces.

\begin{tabular}{lllll}
\hline & DWD & $\begin{array}{l}\text { ECMWF }- \\
\text { deterministic }\end{array}$ & ECMWF - EPS & $\begin{array}{l}\text { Observed } \\
\text { meteorological } \\
\text { data (JRC MARS) }\end{array}$ \\
\hline Temporal resolution & $\begin{array}{l}\text { Staggered, } 1 \mathrm{~h}(1-3 \text { days }), \\
\text { 3 }(4-7 \text { days })\end{array}$ & $\begin{array}{l}\text { Staggered, } 3 \mathrm{~h}(1-3 \text { days }), \\
6 \mathrm{~h}(4-10 \text { days })\end{array}$ & $6 \mathrm{~h}(1-10$ days $)$ & Daily \\
Spatial resolution & Staggered, & $\begin{array}{l}\text { TL511L60 } \\
(\sim 40 \mathrm{~km})\end{array}$ & TL255L40 $(\sim 80 \mathrm{~km}) *$ & Gridded, \\
Times provided & $7 \mathrm{~km}(1-3$ days $)$ and $40 \mathrm{~km}$ & $12: 00 ; 00: 00$ & $12: 00 ; 00: 00$ & $50 \times 50 \mathrm{~km}$ \\
Input fields & $12: 00 ; 00: 00$ & $1(P, T, E)$ & $50+1(P, T, E)$ & $P, T, E_{0}, E S_{0}, E T_{0}$ \\
Bias removal & None $T, E)$ & None & None & None \\
Down-scaling & Dynamic & None & None & None \\
\hline
\end{tabular}

data access rights and a variety of formats and reference systems. EFAS was seen as a possibility to bridge gaps between the different communities for improved information exchange on European level.

Following these needs, a prototype for EFAS was designed and tested in pre-operational mode, with regular requests for feedback from end-users. The involvement of the end-users in the design and content of the products ensured that the EFAS products were readily understood and accepted by the different hydrological partner institutions, as well as more easily integrated into their forecasting practices.

\subsection{Phase 3: Prototype development}

\subsubsection{Data input and collection}

\section{Observed input data}

It was essential for EFAS to establish which data would currently be available on a European scale for setting up, calibrating and validating the hydrological model, as well as which real-time data would be available for daily calculations of the initial conditions at the onset of the forecasts.

Thematic layers describing soil, land use, topography and the river channel network are available at the European Commission Joint Research Centre (JRC). The JRC also holds a meteorological database, hereafter referred to as JRCMARS, with data from 1975 onwards, which is updated daily. Through this database ${ }^{3}$ EFAS has access to meteorological observations from about 2000 stations across Europe, either as station data or as data interpolated onto $50 \times 50 \mathrm{~km}$ grids (Table 1 ). The station density varies greatly from country to country, which can affect the quality of the model results. Currently, the data are collected, quality-checked and transformed into daily values for a $24-\mathrm{h}$ period $(6$ a.m. to 6 a.m.) before they are provided to users at the JRC, which

\footnotetext{
${ }^{3}$ See http://mars.jrc.it/mars/About-us/AGRI4CAST
}

is usually with a 1-2 days delay. Until these data can be collected in real-time, in EFAS the 1-2 days gap between the availability of observed meteorological data and the start of the flood simulations is filled using the most recent meteorological forecast data.

Hydrological observations are currently available only as historic, not real-time, discharge time series. There is a higher spatial coverage for the pilot river basins Elbe and Danube since data collection has focused on these areas. Depending on the river basin and the authority concerned, 70\% to $95 \%$ of the requested data could be collected for the setup of EFAS. Additional data was collected through the databank of the Global Data Runoff Centre ${ }^{4}$, direct contacts with the water authorities, or public websites. In total, data from about 800 stations are now available for the time span 1990 2006, although not all stations have complete records for the full 16 years.

\section{Weather forecasting data}

Weather forecasts are provided by the European Centre for Medium-Range Weather Forecasts (ECMWF, 10-day forecasts, deterministic and ensemble prediction system) and by the Deutsche Wetterdienst (DWD, 7-day forecasts, deterministic only). They correspond to forecasted values of precipitation, temperature and evaporation. Temporal and spatial resolutions of the different data sets are listed in Table 1.

\subsubsection{The hydrological model}

\section{General description}

The hydrological model used for EFAS is LISFLOOD. The model is a hybrid between a conceptual and a physical rainfall-runoff model combined with a routing module in the river channel. LISFLOOD has been specifically designed for large river catchments (de Roo, 1999; van der Knijff and de

\footnotetext{
${ }^{4}$ See http://grdc.bafg.de
} 
Roo, 2006). In particular, it makes use of data layers that are available for the JRC at European scale, such as land use, soil type and texture, river network. These features make the model particularly suited for EFAS and supported its implementation in the forecasting system.

LISFLOOD simulates canopy and surface processes, soil and groundwater system processes and flow in the river channel. In the following paragraphs only the key processes are briefly described. A full description of LISFLOOD can be found in van der Knijff et al. (2008).

Canopy and surface: Snowmelt is simulated using a simple degree-day factor method, also accounting for accelerated snowmelt when it rains (WMO, 1986; Speers and Versteeg, 1979). For the simulation of fast sub-surface flow through macro-pores (preferential flow), it is assumed that the fraction of the water on the soil surface contributing to preferential flow is a non-linear function of the relative saturation of the topsoil, and that the importance of preferential flow increases as the topsoil gets wetter. For the remaining water that falls on the soil surface, infiltration and surface runoff are simulated using the Xinanjiang approach (Zhao and Liu, 1995; Todini, 1996).

Soil and groundwater system: The moisture fluxes out of the top- and subsoil are calculated assuming that the flow is entirely gravity-driven. The groundwater system is described using two parallel interconnected linear reservoirs, similar to the HBV-96 model (Lindström et al., 1997). The upper zone represents a mix of fast groundwater and sub-surface flow, including flow through macro-pores. The lower zone has a much slower response and generates the base-flow.

River channel: Routing of water through the river channel can be simulated with the kinematic or the dynamic wave descriptions (Chow, 1988). Special structures such as water reservoirs and retention areas or polders can be simulated by giving their location, size and in- and outflow boundary conditions.

\section{Setup in EFAS}

For EFAS, LISFLOOD is set up on a $5-\mathrm{km}$ grid, and a $1-\mathrm{km}$ grid for the Elbe and Danube pilot catchments. The 5-km Pan-European setup runs on a pre-operational basis twice a day, while the 1-km setup is used for research only. The temporal resolution used for the model simulations is variable. The calculation of the initial conditions is performed on a daily time step, while the forecasts based on the deterministic weather forecasts are run with a 1-h time-step, and those based on EPS with a 24-h time-step. Model parameters, once defined through optimisation procedures during calibration, remain fixed for each catchment throughout the simulations performed during forecasting. Model parameter uncertainty and its impact on the simulated discharges is the topic of recent studies conducted under the EFAS project (Feyen et al., 2007, 2008). An automatic Bayesian parameter inference algorithm, based on Markov chain Monte Carlo methods, was applied to calibrate the LISFLOOD model for the case-study of the Meuse catchment. It was shown that parameter uncertainty bounds are relatively narrow and that uncertainty assessment could be improved by accounting for more accurate input data errors. In EFAS, as the focus is on medium-range forecasting for early warning, the main part of uncertainty in flood predictions at long lead times is assessed with the use of EPS probabilistic forecasts. Future research aims at contributing for a better knowledge of the total flood prediction limits, by assessing both uncertainties coming from the hydrologic model and from the weather predictions. In this paper, when speaking about uncertainty and probabilities, the authors refer mostly to the uncertainty arising from the input data, and EPS in particular.

Until now EFAS has had to work with limited amount of hydrological data for calibration and validation, and entirely without information for reservoirs and lakes. Although the collection of these data has increased with the increased participation of national water authorities to the EFAS project, detailed information is still not sufficient to serve as input to the hydrological model. Consequently, the calibration of the LISFLOOD model in those river basins where the flow is highly influenced by hydropower or irrigation reservoirs presents some limitations. Model performance is therefore expected to be variable among the European river basins.

\section{Overview on the performance of the hydrological model}

In order to illustrate the influence of observed input data and model calibration in the quality of the hydrological model simulations, we show in Fig. 2 simulated and observed hydrographs for eight river stations in Europe and for different 2-year periods within the time period 1999-2007. The current parameter setup of the LISFLOOD model used in EFAS is at the basis of these simulations. The hydrographs in Fig. 2 show stations where the model performs well, together with stations where problems in reproducing discharge time series are encountered. For instance, it can be seen that discharges simulated for the Danube river are too low comparatively to observed discharges, which can be directly attributed to the low density of rainfall stations in the Alps, resulting in too low annual rainfalls. When comparing the annual total rainfalls from the available JRC-MARS station data with other high resolution data sources, it was observed that the annual rainfall is underestimated with the JRC-MARS database by about $20 \%$ in the Alps. The performance of EFAS at river basins located in the Alpine region is therefore expected to be lower, at least until data collection, currently ongoing, and new parameter calibration will be able to partially correct this bias. We note that although the simulations are not satisfactory in terms of flow volume, the flood dynamics are well captured by the model. Good results both in terms of dynamics and quantity are achieved for most rivers across mid-latitude Europe, e.g. Loire, Seine (not shown), Meuse, Elbe, Weser and Odra (not shown). 


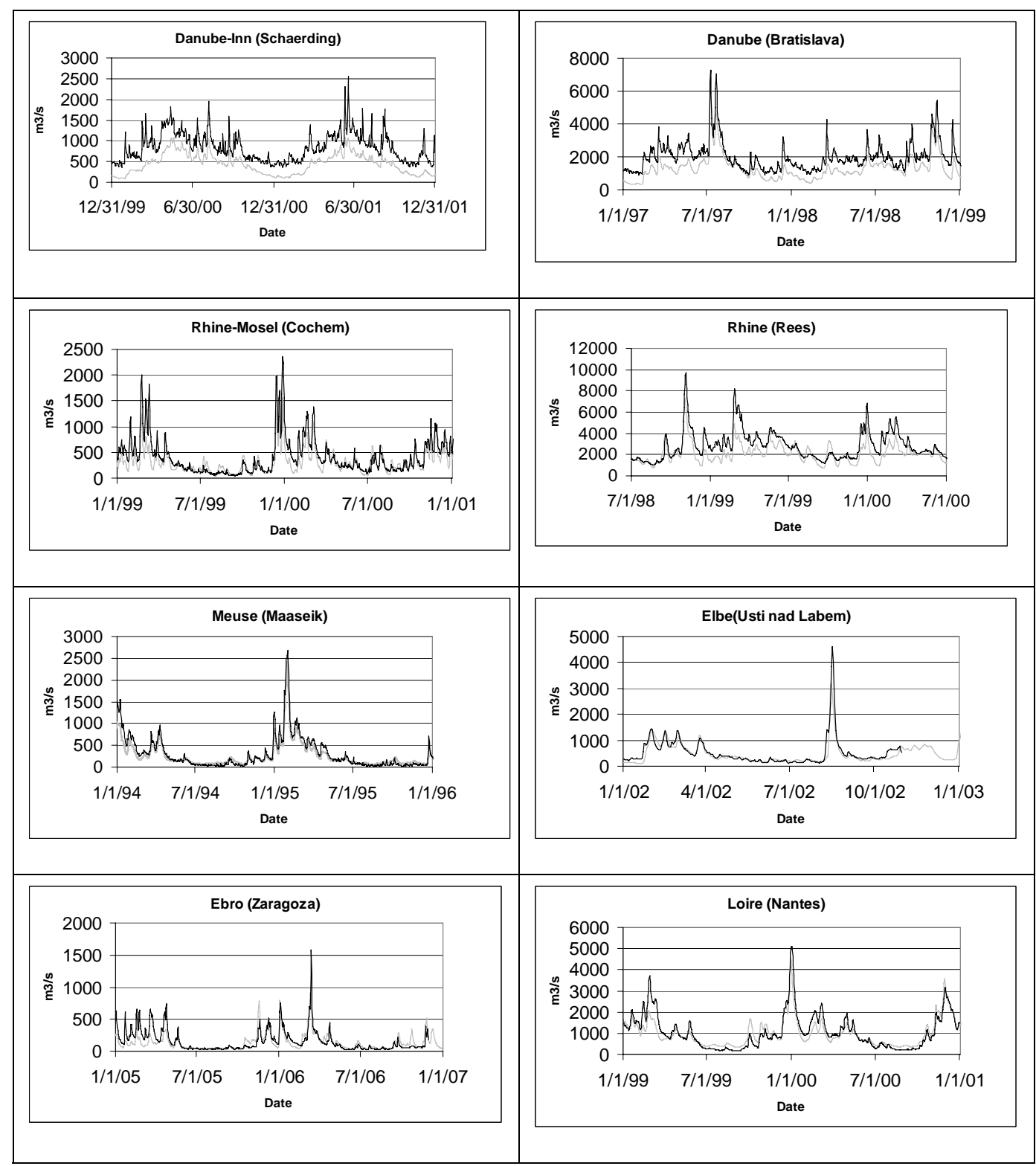

Fig. 2. Simulated (grey lines) and observed (black lines) discharges in $\mathrm{m} 3 / \mathrm{s}$ for different river basins and different 2 year periods.

The variable performance of the hydrological model used in EFAS in reproducing observed discharges is illustrated in Fig. 3. It shows the Nash-Sutcliffe coefficient calculated for 188 selected stations from different river basins across Europe and different upstream areas for all periods where observations were available at the station. The calculation of the Nash-Sutcliffe coefficients includes both validation and calibration periods. The comparison between observed and simulated hydrographs was done for the time period 19902006. More than half of the Nash-Sutcliff values are greater than 0.33 , and $30 \%$ are greater than 0.66 . Clearly, as could be expected from Fig. 2, those river basins strongly affected by the Alps perform less well than those in flatter areas, as is also the case of those stations strongly affected by lakes, reservoirs and hydropower, e.g. in Scandinavia.

Case studies in the pilot river basins, for which detailed and higher resolution data was made available, have clearly demonstrated the link between good quality input data and skill in model performance. Figure 4 shows an example for the Elbe river basin at Dresden. It illustrates the difference in performance when using high resolution national data as compared to low resolution data currently available in realtime for EFAS. One can see that LISFLOOD simulations based on high-resolution data compare quantitatively better 


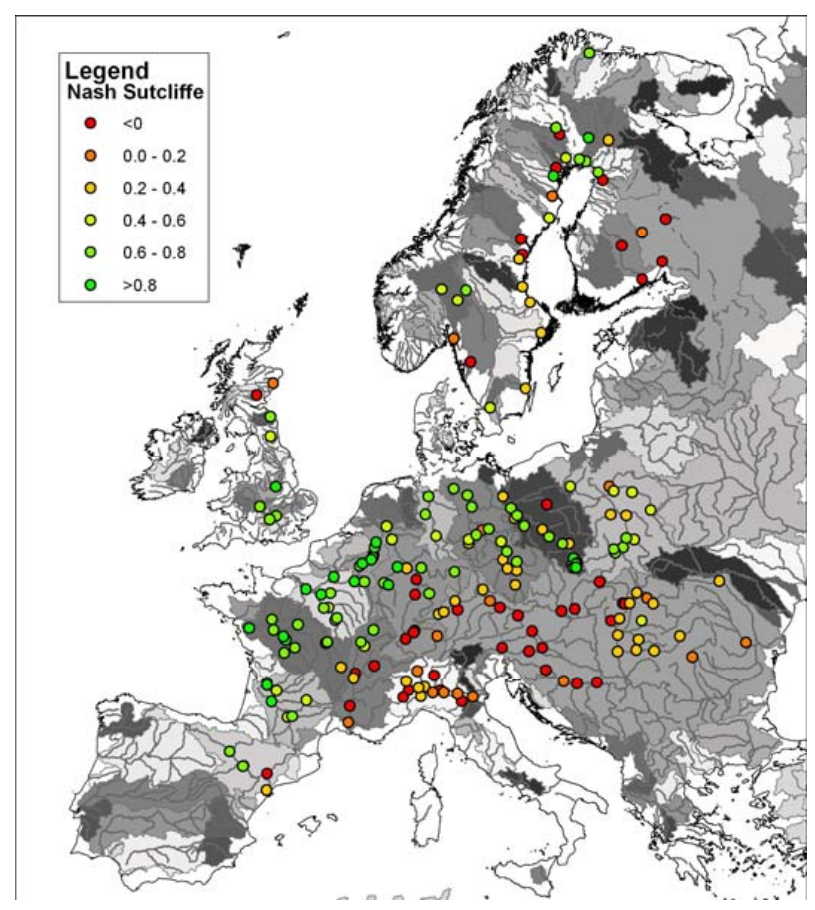

Fig. 3. Nash-Sutcliffe calculated for 188 stations in trans-national river basins (shaded) across Europe.

with the observed discharges than the ones simulated with the coarse rainfall network,. Considering that the maximum average uncertainty for river discharge measurements is often assumed to be on the order of $8.5 \%$ (Pappenberger et al., 2006), and correspondingly more in the peak discharges, the simulations can be considered very good in this flood event case-study. From Fig. 4, it can be seen that the timing of the peak and the overall dynamics of the hydrographs are also very well represented.

In EFAS, special attention has been devoted to the quality of the hydrological simulations, which is considered to play an important role in the quality of the forecasts issued in real-time flood forecasting. However, to assure the good quality of all data necessary to perform hydrological simulations on a European scale is not an easy task. The clear relationship between input data and model performance has prompted the launch of two pan-European data collection projects in support of EFAS, called EU-FLOOD-GIS and the ETN-R project. Both projects collect high-density historic and real-time meteorological and hydrological data necessary for flood forecasting and will become active by the beginning of 2009.
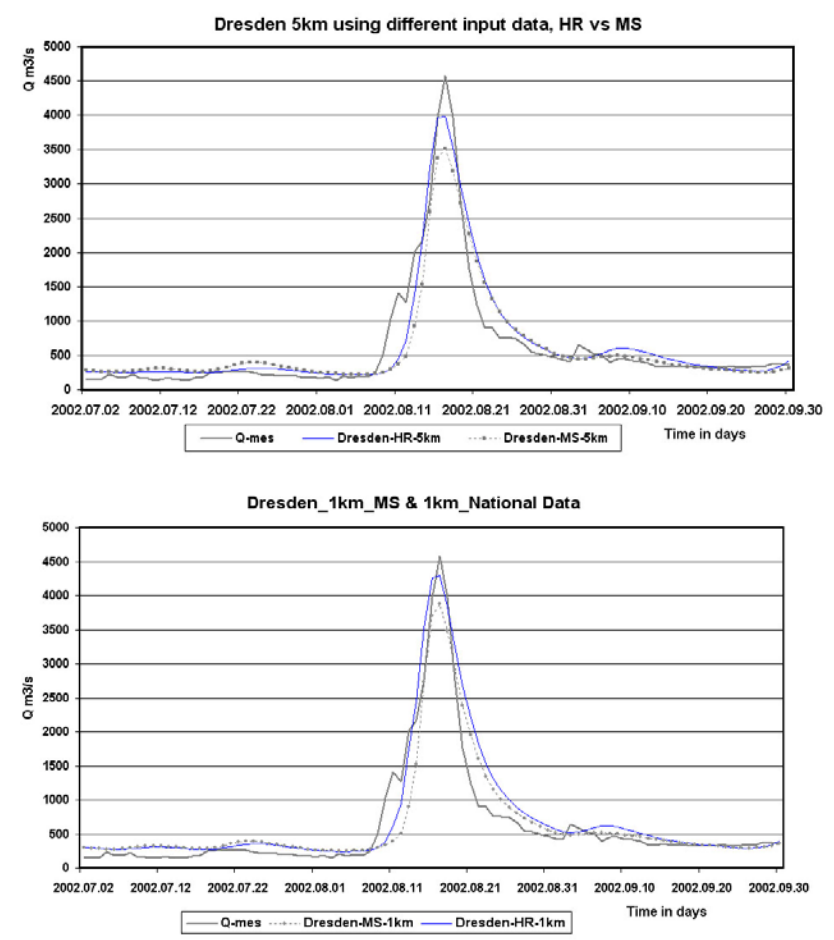

Fig. 4. Hydrographs of observed discharge (solid, grey), simulated discharges with JRC MARS observed data (dotted) and simulated discharges with National high-resolution data (solid blue) at Dresden during the Elbe 2002 floods on a $5 \mathrm{~km}$ grid (top) and a $1 \mathrm{~km}$ grid (bottom).

\subsubsection{Methodologies}

\section{Flood threshold exceedances}

Simulated hydrographs, per se, do not constitute a flood forecast. In order to make a flood forecast, a decision-making element needs to be incorporated: is the discharge going to exceed a critical threshold or not? For the development of the EFAS prototype, the determination of the critical thresholds could not be derived directly from observations.

This is firstly because information on steering rules for lakes, reservoirs, polders or any other measures are not yet available on European scale, and are unlikely to be available in sufficient detail in the future. Thus EFAS treats the river basins as quasi-natural and observed critical thresholds may not be compatible with simulated discharges. Furthermore, results have shown that the limited number of meteorological observations available for EFAS over Europe can lead to large discrepancies between model results and discharge observations, making quantitative comparison between simulated discharges and observed thresholds problematic.

Secondly, EFAS uses the LISFLOOD model with a regular grid structure, and critical values need to be determined at every model grid point. As local critical values are generally 
Table 2. EFAS thresholds, their colour code and associated hazard class

\begin{tabular}{lcl}
\hline EFAS threshold & Colour & Description \\
\hline S (Severe) & $\square$ & Very high possibility of flooding, potentially severe flooding expected. \\
H (High) & $\square$ & High possibility of flooding, bank-full conditions or higher expected. \\
M (Medium) & $\square$ & Water levels high but no flooding expected. \\
L (Low) & $\square$ & Water levels higher than normal but no flooding expected. \\
\hline
\end{tabular}

derived from observations, these are, however, only available at selected gauging stations.

Finally, as illustrated in Figs. 3 and 4, EFAS is currently not able to reproduce hydrographs quantitatively well in all river basins. While the dynamics of the hydrographs may be well simulated, the peak discharges can be systematically too low throughout the annual cycles (e.g. Fig. 2 for Schaerding, Danube). This has to be taken into account when defining critical thresholds for flood warning, otherwise the system will be systematically missing flood events.

To tackle these limitations, a model consistent approach is proposed:

- Based on observed meteorological data, long discharge time series are calculated at each grid with the same LISFLOOD model parameterization that is setup in the forecasting system.

- At each grid, these simulated discharges are ranked and statistically evaluated to get threshold values to be used in EFAS pre-warning.

The critical values obtained with the model consistent approach can be associated with selected return periods or quantiles. In EFAS, the approach used is based on quantiles. In fact, due to the relatively short time series for which reliable meteorological data are currently available (from 1995 onwards), large uncertainties can be expected in the estimation of discharges associated with return periods greater than 2-5 years.

In practice, LISFLOOD simulated discharges are ranked from highest to lowest and cut-off values are chosen as EFAS critical thresholds. Currently, the highest discharge obtained from a 14-year simulation defines the severe threshold level. The discharge value corresponding to the 99th percentile (i.e., $99 \%$ of the simulated discharges are below this value) is chosen as the high threshold level. When comparing this threshold with statistics computed by national hydrologic services at some gauging stations, it was observed that this threshold corresponded repeatedly to return periods of 1 to 2 years. EFAS critical thresholds are coded by different colours and associated with a hazard description, as described in Table 2 .

By taking into account critical thresholds for observed and simulated discharges, discharge time series are then transformed into dichotomous time series of 1 (=Yes, the thresh- old is exceeded) and 0 (=No, the threshold is not exceeded). In forecast verification, these observed and predicted exceedances can then be compared.

The major advantage of the threshold exceedance approach is that the relative difference of simulated discharges to simulated thresholds, but not the actual values, can be assessed, allowing the estimation of the severity of an event qualitatively. The main disadvantage is that the forecasting system may produce reasonable results in terms of threshold exceedances, while being seriously offset from the observed hydrographs. Such quantitative discrepancies need to be identified and reduced over time to ensure that the system remains credible, as well as to make possible the direct use of real-time discharge data in the future implementation of updating procedures. Therefore the continuous feedback from national forecasting centres and the performance of studies comparing simulated discharges with observed data are vital for EFAS. They are necessary for the frequent re-calibration of the system and the production of long-term re-runs for updated critical threshold evaluations. A very similar approach of combining distributed hydrologic modeling with threshold frequency (DHM-TF) has recently been successfully tested in the context of flash-flood forecasting for ungauged river basins by Reed et al. (2007) and also for simulations based on the LISFLOOD model (Younis et al., 2008).

\section{Forecast persistence}

EFAS aims at forecasting large fluvial floods caused mainly by widespread severe precipitation, combined rainfall with snow-melting or prolonged rainfalls of medium intensity. Large synoptic-scale weather phenomena that build up over several days are typically at the origin of these types of severe events. Numerical weather prediction models should therefore pick up these systems not only once, but also in the subsequent days of forecast as the event approaches.

The principle of temporal "persistence" was introduced in EFAS forecasts: a pixel is flagged as "risk of flooding" only if the discharges in that river pixel exceed the EFAS high or EFAS severe flood threshold in three consecutive 12-hourly forecasts. It has been shown that by introducing a criterion of persistence in flood forecasting, the forecast reliability increases (as discussed in detail in Part 2 of this paper: Bartholmes et al., 2009). 

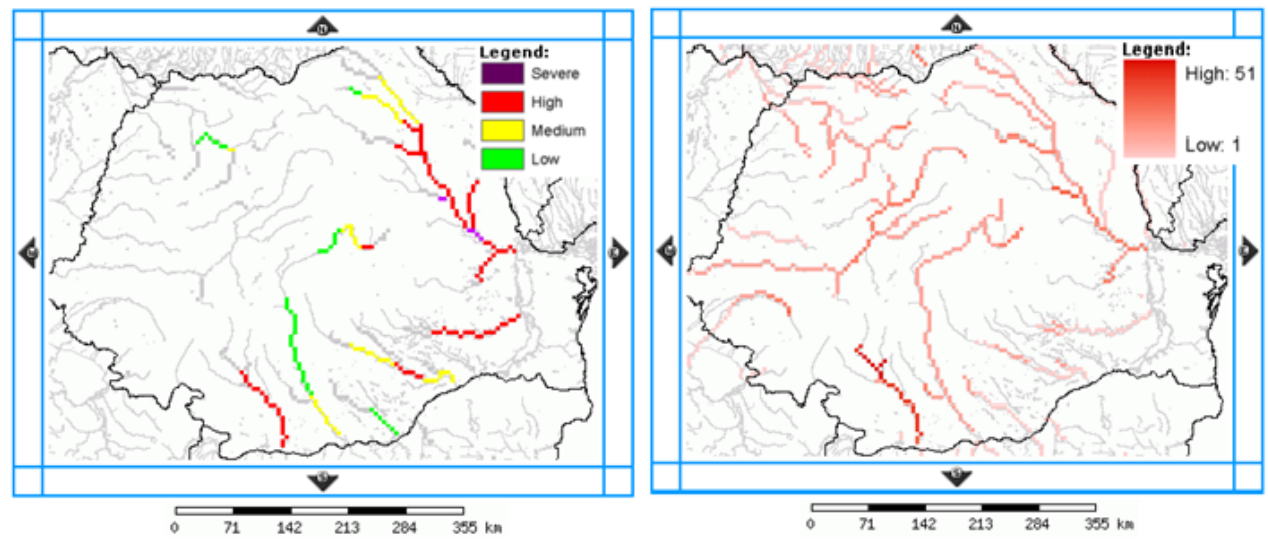

Fig. 5. Example of an EFAS threshold exceedance map based on deterministic forecasts (left) and an EPS-based map showing the number of EPS above EFAS high alert (right).

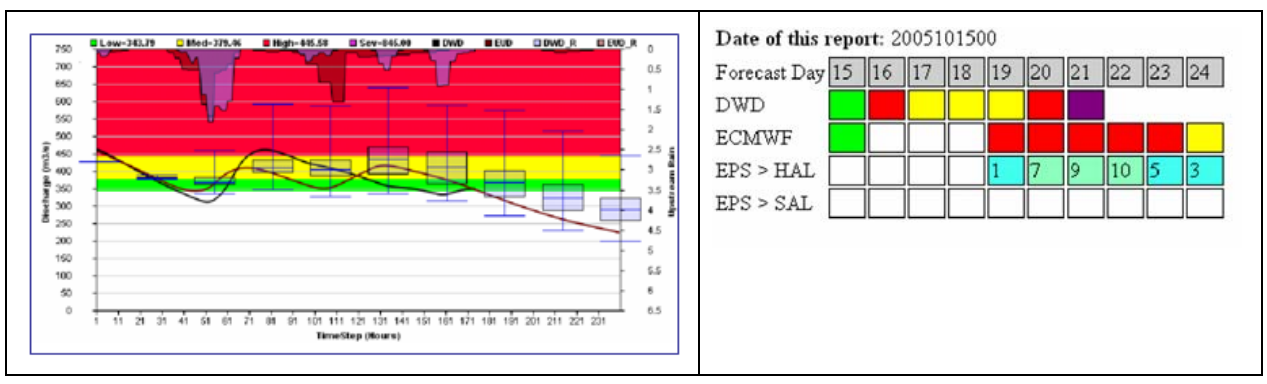

Fig. 6. Left: Hydrographs based on DWD (black) and ECMWF (brown) deterministic forecasts, box-plots (25\%, 50\%, $75 \%$ percentiles) of EPS-based hydrographs. Right: Time series diagram of alert threshold exceedances for one EFAS forecast.

\subsubsection{Visualisation products for ensemble flood forecasting}

Early warning results must be clear, concise and unambiguous in order to be correctly taken into account by the receiving party and lead to action (Demeritt et al., 2007; Buizza, 2008; Lalaurette and van der Grijn, 2002; Thielen et al., 2005). This is particularly important for EFAS information, which is distributed to different authorities across Europe where English, the language adopted in EFAS reports, is not necessarily the native language of the majority of national forecasters. In EFAS, the development of visualisation and decision support products aimed to easily summarise the information issued by the system and to efficient communicate the forecasts to the national hydrological services, helping EFAS users in making decisions on flood warning (Ramos et al., 2007).

EFAS visualisation products focus on threshold exceedances. Overview maps show those river pixels where thresholds are exceeded (Fig. 5, left) or, in the case of forecasts based on probabilistic weather predictions, the number of EPS-based simulations where discharges exceed the EFAS high (Fig. 5, right) or the EFAS severe thresholds (not shown).
For the visualisation of time series of predicted discharges, the so-called spaghetti plots, showing all possible scenarios forecasted, have not been found useful. Instead, the visualisation of pre-processed information such as statistical boxplot representation of quantiles (Fig. 6, left) provides clearer and more concise interpretation of the forecasted situation. In Fig. 6 (left), the y-axis on the left shows discharge $\left(\mathrm{m}^{3} / \mathrm{s}\right)$, and on the right rainfall $(\mathrm{mm})$. Alert thresholds are colourcoded and listed on the top. Upstream rainfall at the pixel is illustrated at the top for DWD (blue) and ECMWF (dark brown).

Figure 6 (right) shows the forecast day (top row, grey), and EFAS threshold exceedances based on DWD and ECMWF forecasts (rows 2-3). The number of EPS-based forecasts exceeding the EFAS high alert (EPS $>$ HAL) and the EFAS severe alert (EPS $>$ SAL) are shown in the two bottom rows. In these colour-coded boxes, only the highest alert threshold exceeded during a $24 \mathrm{~h}$ period is visualised for each deterministic forecast. For the ensemble predictions, both colour codes and numbers are given.

This representation, entirely based on threshold exceedances and containing only the essential early warning information, is the one that is currently disseminated to 

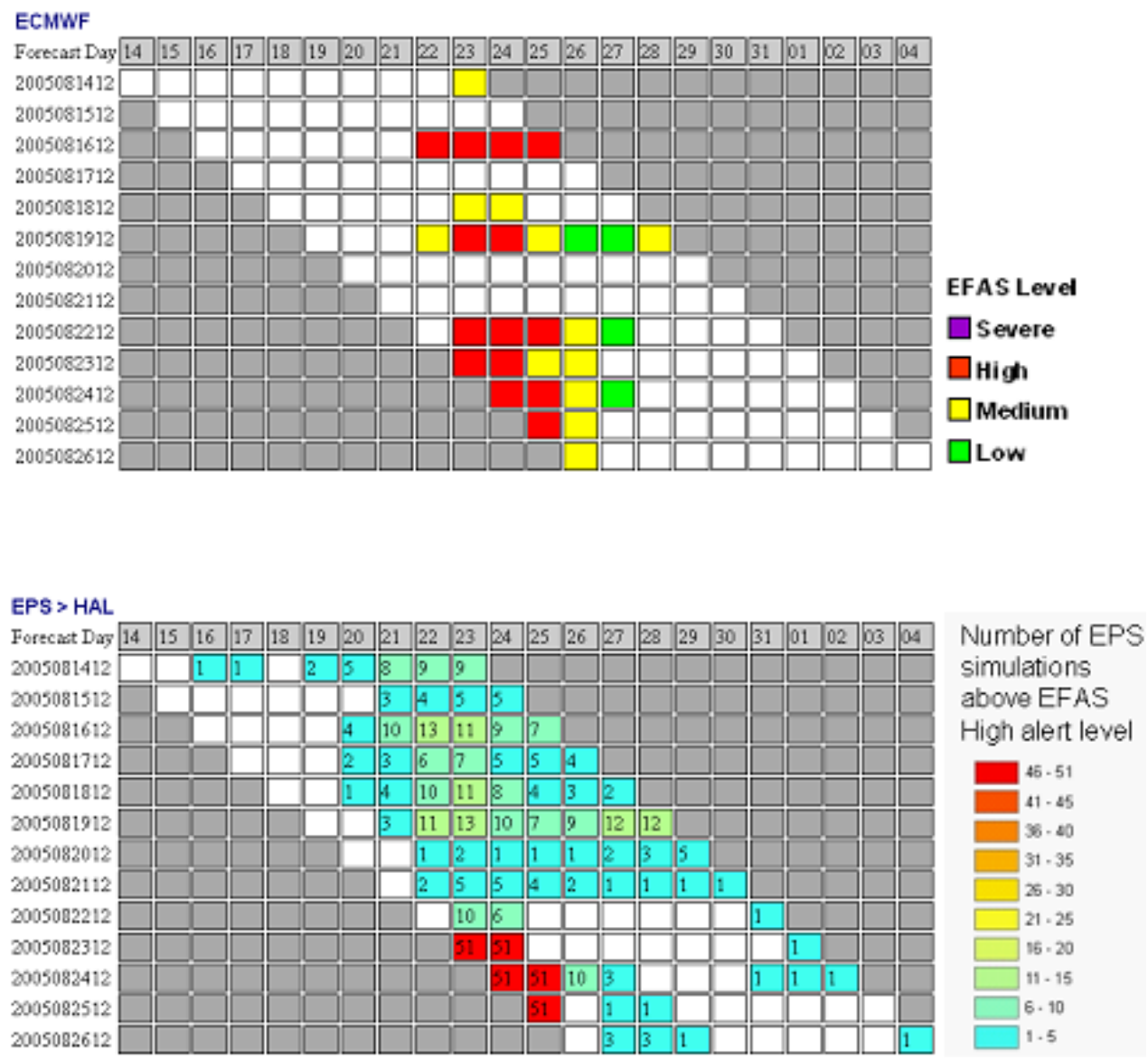

Fig. 7. Persistence of EFAS threshold exceedances based on ECMWF deterministic (top) and persistence of the number of EPS-based forecasts exceeding the EFAS high threshold (bottom).

national forecasting centres. The quantification of uncertainty is intuitively represented (e.g., from Fig. 6, 10 out of 51 EPS reach the EFAS high alert level on the forecast applying to day 22), although, strictly speaking, not yet expressed as probabilities, as all sources of errors in the coupled hydro-meteorological forecasting system are not fully evaluated. Additionally, Gigerenzer (2002) argues that the communication of frequencies is generally easier understood and less misleading than percentages.

Another advantage of the simplified colour-coded box representation is the easy visualisation of persistence of the forecasts. This is illustrated in Fig. 7 for a case study of the 2005 Danube floods in the Isar river (de Roo et al., 2006). It shows EFAS forecasts from 14 August 2005 onwards based on the 12:00 UTC weather forecasts from the deterministic ECMWF forecasts (top) and the probabilistic EPS forecasts (bottom). At this station, threshold exceedances did take place on 22-24 August.

The forecasts based on ECMWF indicate a possibility of flooding for the first time on the 16th August, but the signal becomes intermittent in the subsequent forecasts. The forecasts based on the EPS, however, indicate that there is a chance of flooding in this river quite early on (already from the 14th August) and with relatively good persistence.

Diagrams showing persistence in EFAS forecasts are one of the most frequently used representations that the EFAS forecasters consider in their analyses of the forecasting situation. The have also been considered as very useful and informative by the users of EFAS forecasts at the national forecasting centres.

\subsection{Flood forecasts}

EFAS forecasts run in real-time in order to: (a) test the robustness of the system, and (b) enable decision-making in real-time without the "a priori" knowledge of what has happened. In particular in the context of probabilistic early warning information, it is important to know how much uncertainty is acceptable to practitioners in order to trigger actions, even though the actions may only be of preparatory nature. In the development of EFAS, we considered that only when exposed to EFAS forecasts in real-time and without a 
Table 3. Evaluation of the number of events for which EFAS alerts were sent to the partners during the period from July 2005 to July 2008.

\begin{tabular}{lccccc}
\hline Number of & July-December 2005 & 2006 & 2007 & January-July 2008 & total \\
\hline EFAS alerts & 10 & 20 & 8 & 12 & 50 \\
Flooding Confirmed & 7 & 15 & 6 & 6 & 34 \\
At least bankful confirmed & 0 & 3 & 1 & 2 & 5 \\
False Alarm & 1 & 2 & 1 & 3 & 7 \\
Withdrawn & 1 & 0 & 0 & 0 & 1 \\
No information & 1 & 0 & 0 & 2 & 3 \\
\hline
\end{tabular}

priori knowledge of the accuracy of the forecasts, the utility of the probabilistic information provided could be assessed. Also, in case EFAS forecasts an extreme event, e.g. a record flood, the experience in real-time forecasting would be extremely valuable to acquire the knowledge on how forecasters deal with EFAS information, whether it is considered or disregarded, and how it is in practice used as additional information.

An EFAS forecast is an ensemble of simulations based on the two deterministic weather forecasts from DWD and ECMWF, and a set of 51 EPS members from ECMWF. Since July 2008, regional EPS (Cosmo-LEPS), with 16 members, a spatial resolution of $10 \mathrm{~km}$ and a lead time of 5 days, have also been included.

Based on statistica analysis, a potential flood event has been defined when at least 10 EPS (out of 51) or a deterministic forecast persistently exceed the EFAS high alert threshold. If the event is forecasted persistently in a trans-national river basin and more than $48 \mathrm{~h}$ in advance, an EFAS alert is sent out to all partner organisations sharing the river basin. Products such as maps and combined flood threshold exceedance diagrams, as described earlier in this paper, are also communicated to help the forecasters to make their decisions. Established rules that allow automatic flood alert procedure and that can be used to better guide the expert decision-making are expected to emerge as experience is gained with the forecasting system and to be progressively implemented.

\subsection{Forecast verification}

EFAS results are verified on the basis of: (a) reported flood events (e.g. through partners or media); (b) in-depth case studies for specific strong or severe events; (c) detailed skill score analysis of the performance of the model at the European level and on the basis of long-term time series of archived forecasts issued by the system.

Flood events are monitored using the JRC's Europe Media Monitoring $\left(\mathrm{EMM}^{5}\right)$ facility as well as through observations, when available, or reports from partners.

Table 3 gives an overview of the number of events for which EFAS alerts were sent to the partners during the pe-

\footnotetext{
${ }^{5}$ http://emm.jrc.it
}

riod from July 2005 to July 2008. It also shows the number of confirmed events (flooding and bankful conditions), the number of withdrawn events (i.e., those situations where EFAS issued an early warning but it became clear, with the following forecasts, that the event would not be as severe as first predicted and the alert was withdrawn), as well as the number of false alarms. We note that the flood alerts for the Elbe and Danube river basins are not counted as a single event but broken down into warnings for major tributaries. In total, for 39 out of 50 EFAS early flood warnings, flooding or high water levels were observed and reported, i.e., flood events were confirmed in about $80 \%$ of the cases. When investigating the lead-times of the first EFAS warnings issued, it was observed that, on average, an early warning of 5 days was achieved by the system.

The year 2005 was a flood-prone year in Central Europe, in particular for the Danube river basin, which had several tributaries facing severe floods during the spring and the summer seasons. Although the EFAS partner network was still under development during the first part of the year, and that it was only covering large parts of the river basin by the end of July 2005, the real-time experience with EFAS forecasts was fruitful and even essential to the posterior development of the system's main features. The system captured well the repeated flood events in the Romanian and Bulgarian tributaries of the Danube, as well as the Upper Danube flood events in August 2005 (as reported in detail by de Roo et al., 2006). The unusual long period of colder temperatures over the winter period 2005/2006 resulted in high accumulations of snow over winter. Sudden increase in temperatures in March 2006 combined with considerable amounts of rainfall consequently led to widespread snowmelt driven floods, in particular in the Danube and Elbe river basins. High waters were also observed in the Rhine and other European river basins. The flood events observed in 2007 were also well captured by the system, e.g. the Rhine floods in August and the floods in Romania in October.

Basically, the floods in 2005/2006 showed that the system was technically able to forecast the floods well in advance and report them with leadtimes longer than 2 days to its partners. However, unnecessary delays due to individual reporting reduced the actual leadtime of the system. Therefore, 
Table 4. Survey on use of EFAS information by receiving partner organisations (based on 8 feedback questionnaires from flood alerts in 2005/2006).

\begin{tabular}{|c|c|c|c|}
\hline How was EFAS information used? & & Category & \\
\hline Answers & Early warning & Additional information & Decision making \\
\hline $\begin{array}{l}\text { It was the first warning that focused our attention to that particular } \\
\text { river }\end{array}$ & $\times$ & $\times$ & \\
\hline The reports were useful for the estimation of peak discharge & & $\times$ & \\
\hline $\begin{array}{l}\text { We are using the reports as indication (the local } 48 \mathrm{~h} \text { forecasts from } \\
\text { Meteo-France Aladin and DWD HRM are used in a quantitative } \\
\text { respect) }\end{array}$ & $\times$ & $\times$ & \\
\hline $\begin{array}{l}\text { We get an overview of the situation in the whole catchment, } \\
\text { e.g. which tributaries are affected }\end{array}$ & & $\times$ & \\
\hline it is good to know which general development is predicted by EFAS & $\times$ & $\times$ & \\
\hline $\begin{array}{l}\text { EFAS reports are used to present the hydrological situation in the near } \\
\text { days to institutes responsible for flood protection }\end{array}$ & $x$ & $\times$ & $\times$ \\
\hline EFAS reports were used as orientation information & $x$ & $\times$ & \\
\hline $\begin{array}{l}\text { EFAS reports were used as support to create statement of development } \\
\text { of flood situation }\end{array}$ & & $\times$ & $\times$ \\
\hline
\end{tabular}

a web-based information system, with restricted access for the partners, has been developed and launched in September 2007. This initiative was well received by the partners and many organisations connect regularly to the EFAS webpage, guarantying an effective integration of EFAS information into their regular forecasting procedure.

Additionally, following continuous exchanges with the EFAS partners, it was concluded that false alarms from EFAS are less critical to users than missed events. It was therefore agreed that EFAS alarms would be activated for lower flood probabilities, which could result in more frequent alarms, even if also higher false alarm rates were to be expected. Since the partners can monitor the events online through the new interface, whether or not the event is confirmed as the forecasted date approaches can be directly checked by the partners and an EFAS false alarm can be less harmful for flood preparedness.

In the EFAS framework, case studies are typically looked at in more detail by making use of observations. The analysis of EFAS results for the historic summer 2005 floods in tributaries of the Danube river basin in Austria and Germany are reported by de Roo et al. (2006). A detail case study of the EFAS performance during the spring floods in 2006 in Slovakia, for the Morava River (tributary to the Danube), has been recently published by Kalas et al. (2008), and a case study on the performance of the system during the Elbe floods by Younis et al. (2008). For the 2002 Danube floods, EFAS re-forecasts were produced and Bogner and Kalas (2008) have been looking into novel post-processing methods to remove forecast biases in the outputs and thus produce more reliable results with a reduced, but more meaningful, spread. The analysis of the EFAS performance during the flood events in Romania from 22-25th October 2007 has been recently finalized (Thielen et al., submitted). This event was also subject of a study testing the use of multiple global EPS forecasts (Pappenberger et al., 2008a).

To complement case-study analysis and statistically assess the quality of the forecasts, long time series of forecasts need to be investigated. Detailed statistical skill score analyses represent the core of EFAS forecast verification and, for this purpose, forecast data is continuously archived by the system. Results on the statistical analysis conducted over EFAS forecasts for the period 2005-2007 are presented in Part 2 of this paper (Bartholmes et al., 2009).

\subsection{Impact of EFAS}

When EFAS partners sign the Memorandum of Understanding they agree to receive EFAS forecasts as research products, i.e., products that are still in experimental phase. They are therefore advised not to take public emergency actions based on the information provided by EFAS. During this experimental phase, it is thus difficult to carry out systematic cost benefit analysis on the impact of EFAS forecasts for decision-making at national operational flood forecasting centres. However, the potential usefulness of the warnings launched by the system can be surveyed. In EFAS, this assessment is performed through standardised feedback reports and annual user meetings where partners report on the major flood events they have experienced during the year and the role played by EFAS information in increasing preparedness.

For the flood-prone period of 2005/2006, 8 feedback questionnaires were filled in by the partners and returned to EFAS. Table 4 summarises a preliminary analysis of the answers given by the partners. It shows clearly that most 
partners find EFAS information useful, which was also confirmed by discussions during the annual meetings. Answers on how the EFAS information reports were used in practice were interpreted according to three categories: early warning, additional information and decision making. In general, EFAS results are well perceived by all partners as additional information, contributing to early warning of upcoming floods. A few partners stated that the information was used for actual decision making. In one reported case, a national flood warning was even issued earlier on the basis of EFAS results. In most cases, however, the information is used to discuss and evaluate the current situation, check other data sources and to reschedule working shifts, for example, during weekends. In some cases, EFAS information was also incorporated into communications with local civil protection agencies. Not all partners have access to the same weather forecasts incorporated into EFAS and therefore benefit from the additional information for comparison with their local source information. Many partners reported that it is particularly useful to have information on potential flooding in neighbouring catchments and countries. The feedback received from partners is in general very encouraging for the development of EFAS and has helped in improving the system towards its main goals (Thielen, 2006).

\subsection{Communication platform}

A well established communication platform is crucial for a forecasting system operating on river basins shared by different autonomous administrations. The EFAS communication platform is designed to disseminate results on different levels to EFAS partners and to the public and, equally, to receive feedback from the partners on products and actions taken.

- EFAS partners consist of experts from national hydrological and meteorological services that have agreed to join the EFAS network through the ratification of a Memorandum of Understanding (MoU). MoU's ensure that EFAS results are understood as preliminary research results by the forecasting experts and not as official warnings. Figure 8 shows the trans-national river basins for which at least one EFAS partner organisation currently exists or a MoU is being drafted.

- Except for real-time flood forecasting reports, which are distributed only to EFAS partners, EFAS information is made public in the form of bulletins, scientific communications, publications and reports, which are available at http://efas.jrc.it.

- Feedback from partners to EFAS is captured during annual meetings, feedback forms, and general email exchange. In certain occasions a particular form of feedback engages when EFAS has issued an early flood warning and is contacted directly by the receiving partner for more information or an exchange of information.

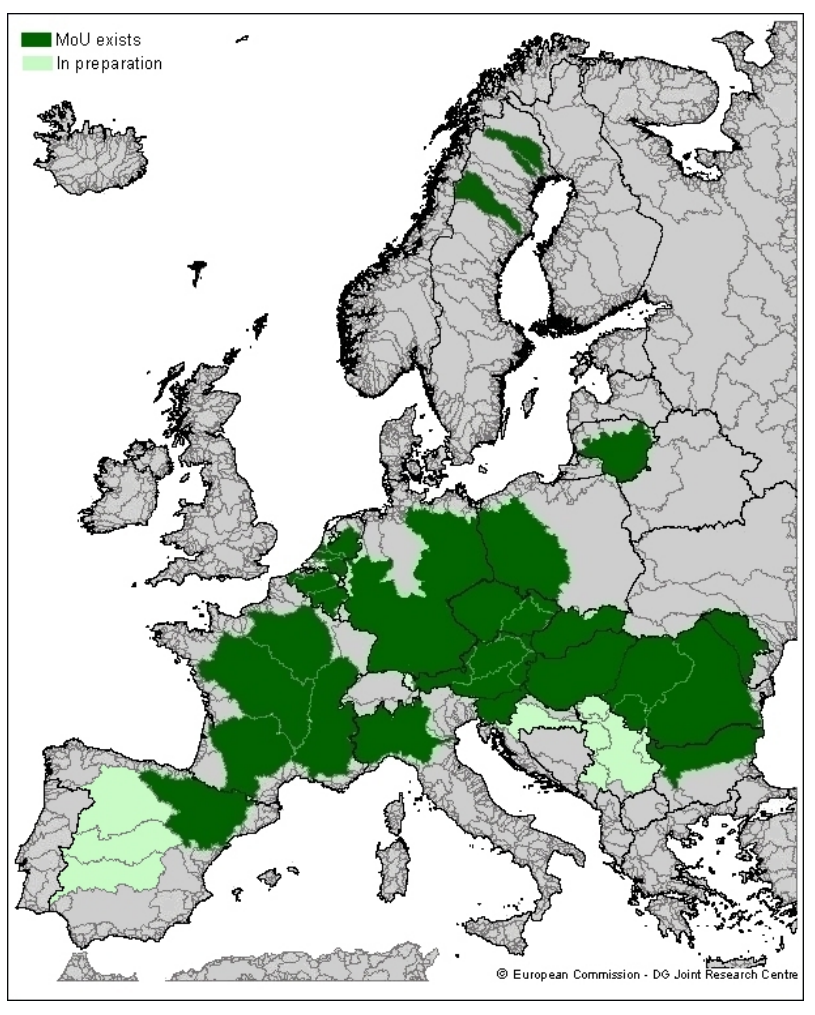

Fig. 8. River basins for which a designated EFAS partner organisation exists or is under negotiation. (Status: December 2007).

\section{Summary and way forward (Phases 4 and 5)}

This paper presented the development of the European Flood Alert System (EFAS). EFAS aims at providing early warning information for floods in Europe with lead-times up to 10 days on the basis of combined deterministic and probabilistic weather information. The development of EFAS followed several stages, starting at a scientific feasibility study, followed by the exploration of the needs of end-users, and finally the development of the system, its products and communication platform. Continuous verification of the model results is an essential part of the system and intense research efforts have been put into it. A detailed analysis of the skill of EFAS forecasts is described in Part 2 of this paper (Bartholmes et al., 2009).

The core of EFAS consists of a grid-based distributed hydrological rainfall-runoff model with a routing component that is capable of simulating hydrological processes in large river basins. This model is fed with several medium-range weather forecasts, including full sets of Ensemble Prediction System (EPS). The multi-streamflow output is analysed and visualised through concise and easy to understand products developed together with users to be complementary to information already produced by local water authorities. A communication strategy and platform was also developed. 
It allows interactive exchange with different EFAS partners and national stakeholders, including meteorological data providers and national water authorities.

Through the creation of the communication network, another important component of the system could be more easily approached: the streamflow data collection and storage. This is a necessary step to calibrate the hydrological model and to determine the initial conditions at the start of the flood forecasts. Since the implementation of the first prototype of the system, new projects have been launched to collect more data and contribute to progress in the development of the system.

In the future, the system will also incorporate new weather forecast data, particularly ensemble predictions with higher resolutions and longer leadtimes (see for example Tibaldi et al., 2006 and Buizza et al., 2007). The aim is to continuously test, together with EFAS partners, the additional value of these state-of-the-art meteorology products for operational flood forecasting.

The first EFAS prototype has been running preoperationally since 2005 and its results have been analyzed in order to assess the average performance of the system in detecting potential flood events and its capabilities to complement Member States' activities. The transfer from a research pre-operational tool to a fully operational system will be explored in the near future.

Once fully developed and tested, EFAS will not only provide early flood alert information to the national hydrological forecasting services, but it will also represent a powerful tool for the European Commission and the Member States' authorities for monitoring hydrological conditions across Europe, analysing climatology and trends over the past years based on a consistent and homogeneous platform, as well as for forecasting possible future trends when coupled with seasonal forecasts and climate change model outputs. Furthermore, because of the trans-boundary nature of the EFAS simulations, it could be anticipated that exchange of flood forecasting experiences, data and research practices would be favoured within the platform.

It is expected that by 2010 EFAS has matured to a fully operational system that can be transferred to an operational entity. An important part of this process will be the establishment of unique European databases for hydrological and meteorological data relevant for flood forecasting (EU-FLOODGIS and ETN-R).

EFAS is currently one of the few (pre)operational flood warning systems worldwide making use of ensemble prediction systems to increase the predictability of floods. There is evidence that the project has contributed on a whole to accelerate the adoption of an ensemble hydrological prediction approach also in national and regional flood forecasting systems in Europe.
Acknowledgements. The authors gratefully acknowledge the support of all staff of the DG JRC's Institute for Environment and Sustainability (IES) - FLOODS action, and the IT support of the Institute's Land Management and Natural Hazard Unit. Particular thanks are expressed to the authorities of those countries that provided detached national experts to the DG JRC for the development of the EFAS prototype (i.e. Austria, Czech Republic, Germany, Hungary and Slovakia). The authors also wish to thank the German Weather Service, the European Centre for Medium-Range Weather Forecasts, and the JRC's Institute for Protection and Security of the Citizen (IPSC) for providing data. Finally all EFAS partner organizations must be thanked for their interest, active support and feed-back without which the development of the system would not have been successful. J. Younis and B. Pannemans are thanked for for providing material for this paper, F. Pappenberger and N. McCormick for reviewing this manuscript. For their financial support the authors thank the European Parliament, DG Environment and DG Enterprise.

Edited by: L. Pfister

\section{References}

Bakker, M. H. N.: Transboundary river floods: vulnerability of continents, international river basins and countries. Ph.D Dissertation, Oregon State University, 276 http://hdl.handle.net/1957/ 3821, 2007.

Bartholmes, J. and Todini, E.: Coupling meteorological and hydrological models for flood forecasting, Hydrol. Earth Syst. Sci., 9, 333-346, 2005,

http://www.hydrol-earth-syst-sci.net/9/333/2005/.

Bartholmes, J. C., Thielen, J., Ramos, M. H., and Gentilini, S.: The European Flood Alert System EFAS - Part 2: Statistical skill assessment of probabilistic and deterministic operational forecasts, Hydrol. Earth Syst. Sci., 13, 141-153, 2009, http://www.hydrol-earth-syst-sci.net/13/141/2009/.

Bogner, K. and Kalas, M.: Error correction methods and evaluation of an ensemble based hydrological forecasting system for the Upper Danube catchment, Atmos. Sci. Lett., 9, 95-102, 2008.

Brázdil, R., Pfister, C., Wanner, H., von Storch, H., and Luterbacher, J.: Historical climatology in Europe - The state of the art, Clim. Change, 70, 363-430, 2005.

Buizza, R., Bidlot, J.-R., Wedi, N., Fuentes, M., Hamrud, M., Holt, G., and Vitart, F.: The new ECMWF VAREPS, Q. J. Roy. Meteorol. Soc., 133, 681-695, 2007.

Buizza, R.: The value of probabilistic prediction, Atmos. Sci. Lett., 9, 36-42, 2008.

Buizza, R., Hollingsworth, A., Lalaurette F., and Ghelli, A.: Probabilistic Predictions of Precipitation Using the ECMWF Ensemble Prediction System, Weather and Forecasting, 14, 168-189, 1999.

Chow, V. T., Maidment, D. R., and Mays, L. M.: Applied Hydrology, McGraw-Hill, Singapore, p. 572, 1988.

De Roo, A., Gouweleeuw, B., Thielen, J., Bates, P., Hollingsworth, A., et al.: Development of a European Flood Forecasting System, International Journal of River Basin Management, 1(1), 49-59, 2003.

De Roo, A.: LISFLOOD: a rainfall-runoff model for large river basins to assess the influence of land use changes on flood risk, in: Ribamod: river basin modelling, management and flood mit- 
igation, edited by: Balabanis, P., Concerted action, European Commission, EUR 18287 EN, 349-357, 1999.

De Roo, A., Ramos, M. H., Thielen, J., Franchello, G., Bartholmes, J., Wachter, K., Niemeyer, S., Kalas, M., Laguardia, G., and van der Kniff, J.: The Alpine floods of August 2005, What did EFAS forecast, what was observed, which feedback was received from end-users? EFAS Post-event summary report, European Commission, EUR 22154 EN, p. 94, 2006.

Demeritt, D., Cloke, H., Pappenberger, F., Thielen, J., Bartholmes, J., and Ramos, M. H.: Ensemble Prediction and perception of risk, uncertainty and error in flood forecasting, Environmental Hazards, 7, 115-127, 2007.

EEA, European Environment Agency: Mapping the impacts of recent natural disasters and technological accidents in Europe, Environmental issue report No. 35, European Environment Agency, Copenhagen, p. 47, 2003.

Feyen, L., Vrugt, J. A., Ó Nualláinc, B., van der Knijff, J., and de Roo, A.: Parameter optimisation and uncertainty assessment for large-scale streamflow simulation with the LISFLOOD model, J. Hydrol., 332(3-4), 276-289, 2007.

Feyen, L., Kalas, M., and Vrugt, J. A.: Semi-distributed parameter optimization and uncertainty assessment for large-scale streamflow simulation using global optimization, Hydrol. Sci. J., 53(2), 293-308, 2008.

Franz, K., Ajami, N., Schaake, J., and Buizza, R.: Hydrologic Ensemble Prediction Experiment Focuses on Reliable Forecasts, Eos, 86(25), AGU, 2005.

Gigerenzer, G.: Calculated risk. How to know when numbers deceive you, Simon and Schuster, New York, p. 310, 2002.

Goubanova, K. and Li, L.: Extremes in temperature and precipitation around the Mediterranean basin in an ensemble of future climate scenarios simulations, Global Planet. Change, 57, 27-42, 2007.

Gouweleeuw, B., Reggiani, P., and De Roo, A.: A European Flood Forecasting System EFFS. Full Report, European Report EUR 21208, EC DG JRC \& WL Delft Hydraulics, p. 304, 2004.

Gouweleeuw, B. T., Thielen, J., Franchello, G., De Roo, A. P. J., and Buizza, R.: Flood forecasting using medium-range probabilistic weather prediction, Hydrol. Earth Syst. Sci., 9, 365-380, 2005, http://www.hydrol-earth-syst-sci.net/9/365/2005/.

Hamill, T., Clark, M., Schaake, J., and Buizza, R.: 2nd HEPEX Workshop Summary Report, Boulder, Colorado. http://hydis8. eng.uci.edu/hepex/scndwksp/HEPEX05-Summary.pdf, 2005.

ICPDR, International Commission for the Protection of the Danube River Basin: Flooding fears return to the Danube, Danube Watch, 2, 14-15, 2006.

Kalas, M., Ramos, M. H., Thielen J., and Babiakova, G.: Evaluation of the medium-range European flood forecasts for the MarchApril 2006 flood in the Morava River, Journal of Hydrology and Hydromechanics, 56(2), 116-132, 2008.

Kowalski-Trakofler, K. M., Vaught, C., and Scharf, T.: Judgment and decision making under stress: an overview for emergency managers, Int. J. Emergency Management, 1(3), 278-289, 2003.

Kwadijk, J.: EFFS - European Flood Forecasting System, Final report of Contract EVG1-CT-1999-00011 (http://effs.wldelft.nl), 2003.

Lalaurette, F. and van der Grijn, G.: Ensemble forecasts: can they provide useful early warnings? ECMWF Newsletter 96, 10-18, Winter 2002/2003, 2002.
Lehner, B., Doll, P., Alcamo, J., Henrichs, T., and Kaspar, F.: Estimating the impact of global change on flood and drought risks in Europe: a continental, integrated analysis, Clim. Change, 75, 273-299, 2006.

Lindström, G., Johansson, B., Persson, M., Gardelin, M., and Bergström, S.: Development and test of the distributed HBV-96 hydrological model, J. Hydrol., 201, 272-288, 1997.

Marsigli, C., Montani, A., Nerozzi, F., Paccagnella, T., Tibaldi, S., Molteni, F., and Buizza, R.: A strategy for high-resolution ensemble prediction, II: Limited-area experiments in four Alpine flood events, Q. J. Roy. Meteorol. Soc., 127, 2095-2115, 2001.

Marsigli, C., Boccanera, F., Montani, A., and Paccagnella, T.: The COSMO-LEPS mesoscale ensemble system: validation of the methodology and verification, Nonlin. Processes Geophys., 12, 527-536, 2005, http://www.nonlin-processes-geophys.net/12/527/2005/.

Milly, P. C. D., Wetherald, R. T., Dunne, K. A., and Delworth, T. L.: Increasing risk of great floods in a changing climate, Nature, 415, 514-517, 2002.

Molteni, F., Buizza, R., Palmer, T. N., and Petroliagis, T.: The ECMWF ensemble prediction system: methodology and validation, Q. J. Roy. Meteorol. Soc., 122, 73-119, 1996.

Palmer, T. N. and Raisanen, J.: Quantifying the risk of extreme seasonal precipitation events in a changing climate, Nature, 415, 512-514, 2002.

Pappenberger, F., Matgen, P., Beven, K. J., Henry, J.-B., Pfister, L., and Fraipont, P.: Influence of uncertain boundary conditions and model structure on flood inundation predictions, Adv. Water Resour., 29(10), 1430-1449, 2006.

Pappenberger, F., Bartholmes, J., Thielen, J., Cloke, H., Buizza, R., and de Roo, A.: New dimensions in early flood warning across the globe using grand-ensemble weather predictions, Geophys Res. Lett., 35, L10404, doi:10.1029/2008GL033837, 2008a.

Pappenberger F., Scipal, K., and Buizza, R.: Hydrological aspects of meteorological verification, Atmos. Sci. Lett., 9, 43-52, 2008b.

Paton, D. and Flin, R.: Disaster Stress: an emergency management perspective, Disaster Prevention and Management, 8(4), 261267, 1999.

Reed, S., Schaake, J., and Zhang, Z.: A distributed hydrologic model and threshold frequency based method for flash flood forecasting at ungauged locations, J. Hydrol., 337(3-4), 402-420, 2007.

Ramos, M. H., Bartholmes, J., and Thielen-del Pozo, J.: Development of decision support products based on ensemble weather forecasts in the European Flood Alert System, Atmos. Sci. Lett., 8, 113-119, 2007.

Roulin, E.: Skill and relative economic value of medium-range hydrological ensemble predictions, Hydrol. Earth Syst. Sci., 11, 725-737, 2007, http://www.hydrol-earth-syst-sci.net/11/725/2007/.

Schaake, J., Franz, K., Bradley, A., and Buizza, R.: The Hydrologic Ensemble Prediction EXperiment (HEPEX), Hydrol. Earth Syst. Sci. Discuss., 3, 3321-3332, 2006, http://www.hydrol-earth-syst-sci-discuss.net/3/3321/2006/.

Schaake, J. C., Hamill, T. M. , Buizza, R., and Clark, M.: HEPEX, the Hydrological Ensemble Prediction Experiment, B. Am. Meteor. Soc., 88(10), 1541-1547, 2007.

Speers, D. D. and Versteeg, J. D.: Runoff forecasting for reservoir 
operations - the past and the future. In Proceedings 52nd Western Snow Conference, 149-156, 1979.

Tibaldi, S., Paccagnella, T., Marsigli, C., Montani, A., and Nerozzi, F.: Limited-Area Ensemble Forecasting: the COSMO-LEPS System, Predictabilty of Weather and Climate, CAMBRIDGE University Press, 2006.

Thielen, J., de Roo, A., and Schmuck, G.: First LISFLOOD ALERT workshop - practical benefit from European research, http://efas.jrc.it/workshop2003/reports/ Summary-Report-1st_EFAS-ws.pdf, 2003.

Thielen, J., Ramos, M. H., Bartholmes, J., De Roo, A., Cloke, H., Pappenberger, F., and Demeritt, D.: Summary report of the 1st EFAS workshop on the use of Ensemble Prediction System in flood forecasting, 21-22nd November 2005, Ispra. European Commission, Report, EUR 22118 EN (http://efas.jrc.it/ workshop2005/index.html), p. 23, 2005.

Thielen, J.: The benefit of probabilistic flood forecasting on European scale - Results of the European Flood Alert System for 2005/2006; European Commission, EUR 22560 EN, (http://efas. jrc.ec.europa.eu/downloads/efas2005-2006EUR22560EN.pdf), 2006.

Thielen, J., Bartholmes, J., and Schaake, J.: 3rf HEPEX workshop, Book of Abstracts, European Commission, Report, EUR22861 EN, http://hydis8.eng.uci.edu/hepex/thrdwksp/ thrdwksp.html, 2007.

Thielen, J., Schaake, J., Hartman, R., and Buizza, R.: Aims, challenges and progress of the Hydrological Ensemble Prediction Experiment (HEPEX) following the third HEPEX workshop held in Stresa 27 to 29 June 2007, Atmos. Sci. Lett., 9, 29-35, 2008.
Tracton, M. S. and Kalnay E.: Operational ensemble prediction at the National Meteorological Center: Practical aspects, Weather Forecasting, 8, 379-398, 1993.

Todini, E.: The ARNO rainfall-runoff model, J. Hydrol., 175, 339_ 382. 1996

Toothill, J.: Central European Flooding August 2002, Technical Report EQECAT, ABS Consulting, 2002, 21 pp., 2002.

Van Der Knijff, J. and De Roo, A.: LISFLOOD - distributed water balance and flood simulation model, User manual (version December 2005), European Commission, EN22166, p. 80, 2006.

Van der Knijff, J. M., Younis, J., and de Roo, A. P. J.: LISFLOOD: a GIS-based distributed model for river basin scale water balance and flood simulation, Int. J. Geographical Information Science, 1-24 November, 2008.

World Meteorological Organization: Intercomparison of models of snowmelt runoff, Operational Hydrology Report No. 23, 1986

Yiou, P., Ribereau, P., Naveau, P., Nogaj, M., and Brázdil, R.: Statistical analysis of floods in Bohemia (Czech Republic) since 1825, Hydrol. Sci. J., 51(5), 930-945, 2006.

Younis, J., Ramos, M.-H., and Thielen J.: EFAS forecasts for the March-April 2006 flood in the Czech part of the Elbe River Basin - a case study, Atmos. Sci. Lett., 9, 88-94, 2008.

Younis, J., Anquetin, S., and Thielen, J.: The benefit of highresolution operational weather forecasts for flash flood warning, Hydrol. Earth Syst. Sci., 12, 1039-1051, 2008, http://www.hydrol-earth-syst-sci.net/12/1039/2008/.

Zhao, R. J. and Liu, X. R.: The Xinanjiang model, in: Computer Models of Watershed Hydrology, edited by: Singh, V. P., 215232, 1995. 